\title{
Estudo da Potencialidade da Produção de Adoquim com Massa Cerâmica Utilizada em Telhas Prensadas
}

\author{
Diego Silva Ferreira ${ }^{a *}$, Renan Maycon Mendes Gomes $^{b}$, Wendel Melo Prudêncio Araújoc, \\ Roberto Arruda Lima Soares ${ }^{d}$ \\ ${ }^{a}$ Centro Universitário Santo Agostinho - UNIFSA, Teresina, PI, Brasil \\ ${ }^{b}$ Centro Universitário Novafapi - UNINOVAFAPI, Teresina, PI, Brasil \\ 'Universidade Federal do Pará - UFPA, Belém, PA, Brasil \\ ${ }^{d}$ Instituto Federal do Piauí - IFPI, Teresina, PI, Brasil \\ *e-mail: diegof.engenheiro@gmail.com
}

\begin{abstract}
Resumo
Este trabalho teve como objetivo avaliar a produção de um pavimento cerâmico, conhecido como adoquim, utilizando massa cerâmica de telhas prensadas. A matéria-prima foi caracterizada por fluorescência de raios $\mathrm{X}$, difração de raios X, análise termogravimétrica e quanto a plasticidade. Moldou-se os corpos de prova por prensagem nas dimensões 250x125x80mm e em seguida foram queimados nas temperaturas de $950{ }^{\circ} \mathrm{C}, 1050{ }^{\circ} \mathrm{C}$ e $1150{ }^{\circ} \mathrm{C}$. Avaliou-se os corpos de prova sinterizados quanto a retração linear de queima, massa específica aparente, absorção de água e resistência à compressão. Analisou-se também após queima a microestrutura por difração de raios X e a microscopia eletrônica de varredura. Os resultados demonstraram que o adoquim produzido na temperatura de $1150{ }^{\circ} \mathrm{C}$ apresentou os melhores resultados dentre as três temperaturas de queima estudadas, demonstrando um grande potencial o uso dessa massa argilosa na fabricação de Adoquim.
\end{abstract}

Palavras-chave: pavimento, massa cerâmica, queima.

\section{Introdução}

A abundância de matérias-primas naturais, fontes alternativas de energia e disponibilidade de tecnologias práticas ligadas aos equipamentos industriais, fizeram com que as indústrias cerâmicas brasileiras evoluíssem muito rápido e muitos tipos de produtos dos diversos segmentos cerâmicos atingissem nível de qualidade internacional ${ }^{1}$.

As cerâmicas piauienses, de modo geral, apresentam produção de blocos de vedação, telhas, lajotas, blocos estruturais e peças decorativas, com destaque na produção de telhas e tijolos, mas não apresenta produto cerâmico voltado para utilização em passeios e vias públicas.

O processo de inovação deve ser contínuo e é fundamental para a indústria cerâmica conservar e incrementar a sua competitividade, pois, além de estratégia direcionada ao aumento de produção e otimização de custos, também melhora o uso dos recursos minerais e tecnológicos existentes ${ }^{2}$. Dessa forma, o crescimento do desenvolvimento do setor cerâmico do Piauí, em especial da Grande Teresina, demanda a introdução de novos produtos com alto valor agregado. $\mathrm{O}$ adoquim cerâmico destaca-se como potencial inovador, além de possibilitar aproveitamento de resíduos da própria indústria cerâmica, como o chamote, e de outros tipos de indústrias como matéria-prima para sua confecção.

$\mathrm{O}$ adoquim cerâmico é um pavimento intertravado que apresenta inúmeras características benefícios como uma grande vida útil, elevada resistência mecânica, cores naturais e facilidade de implantação e reparação, tendo em vista que as obras podem ser liberadas ao tráfego imediatamente após a execução.

Portanto, as características do adoquim associadas ao fator do Piauí apresentar uma das melhores argilas vermelhas do país, despertou o interesse do meio acadêmico para o desenvolvimento deste pavimento para atender o mercado local, utilizando a matéria-prima das telhas prensadas.

\section{Material e Métodos}

\subsection{Matéria-Prima}

$\mathrm{Na}$ elaboração deste estudo, foi utilizada como matéria-prima a massa argilosa coletada em uma indústria cerâmica na região da Grande Teresina. Obteve-se do silo da indústria aproximadamente $150 \mathrm{~kg}$ da argila utilizada para a fabricação de telhas prensadas, já moída e peneirada na peneira de \#50 mesh, onde foram ensacadas em sacos de polipropileno e acondicionadas em laboratório.

Procedeu-se com o quarteamento de todo o material colhido para obtenção de uma amostra representativa, em torno de $2 \mathrm{~kg}$. Encaminhou-se em seguida para a estufa a temperatura de $110{ }^{\circ} \mathrm{C}$ para os ensaios de análises químicas, mineralógicas e físicas.

Foram analisadas as seguintes características da matéria-prima;

Limite Liquidez;

Limite de Plasticidade; 
$>$ Índice de Plasticidade;

Fluorescência de Raios X;

Difração de Raios X;

Análise Térmica.

A execução dos ensaios da mistura argilosa coletada e a utilização da aparelhagem seguiram as padronizações das ABNT NBR 6459/16 $6^{3}$ e NBR 7180/16.

$\mathrm{O}$ ensaio de fluorescência de raios $\mathrm{X}$ por energia dispersiva foi realizado no espectrômetro por fluorescência de raios modelo Epsilon 3 - XL da PANalytical, presente no laboratório de materiais do IFPI. O ensaio de difração de raios $\mathrm{X}$ foi realizado utilizando-se amostragem em pó, no equipamento XRD-6000 Shimadzu com tubo de $\mathrm{Cu}\left(\lambda=1,54056 \mathrm{~A}^{\circ}\right)$. A tensão utilizada foi de $40 \mathrm{kV}$ e a corrente foi de $30 \mathrm{~mA}$, com varredura de $2^{\circ}$ a $80^{\circ}$ para $2 \theta$, com velocidade de $2 \%$ min e passo de $0,02^{\circ} /$ passo.
A avaliação térmica da matéria-prima foi realizada no Analisador Termogravimétrico TGA-51H SHIMADZU alocado no laboratório de materiais do IFPI. Para a análise, foi utilizada em torno de $15 \mathrm{mg}$ da mistura argilosa, com granulometria inferior a 200 mesh, sob um fluxo de ar sintético de $50 \mathrm{~mL} / \mathrm{min}$. A taxa de aquecimento foi de $10^{\circ} \mathrm{C} /$ min entre $27^{\circ} \mathrm{C}$ e $1150^{\circ} \mathrm{C}$. A análise dos resultados e a obtenção da curva derivada da TG denominada DTG, foram realizadas utilizando-se o programa de computador denominado TA-60 WS Collection, para análises térmicas da SHIMADZU.

Realizou-se o ensaio de água residual para a identificação da quantidade de água a adicionar para a moldagem dos corpos de prova por prensagem. No processo de prensagem dos corpos de prova com dimensões de 250x125x80mm, utilizou-se a prensa manual Verde Equipamentos, figura 1a, e para a queima utilizou-se o Forno Jung modelo LF10014, figura $1 \mathrm{~b}$ com taxa de aquecimento de $2{ }^{\circ} \mathrm{C}$ por minuto com patamar de 90 minutos nas temperaturas de $950^{\circ} \mathrm{C}$, $1050^{\circ} \mathrm{C}$ e $1150{ }^{\circ} \mathrm{C}$, figura $2 \mathrm{a}, \mathrm{b}$ e c.

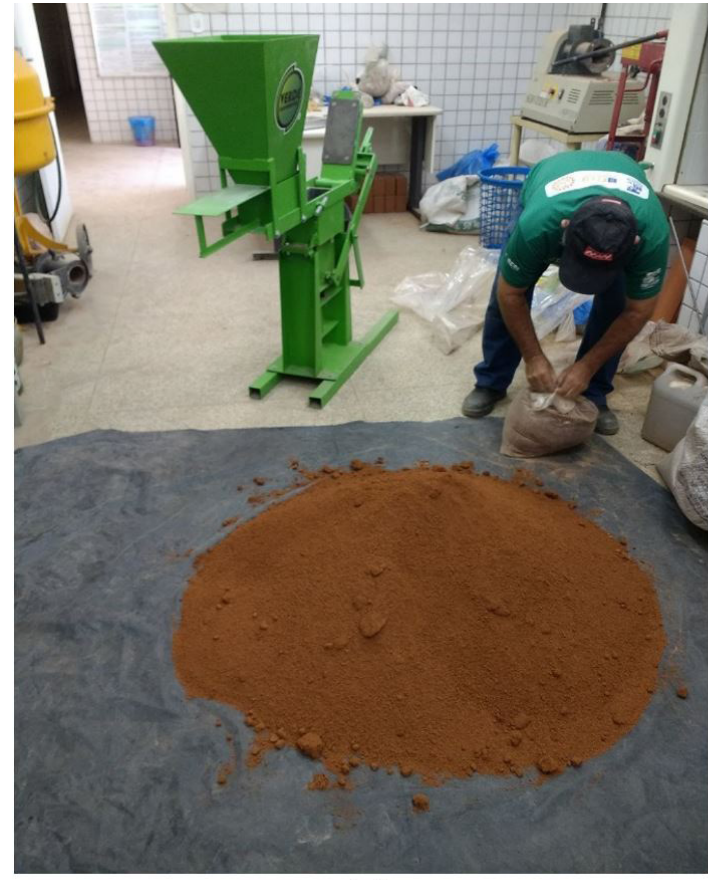

(a)

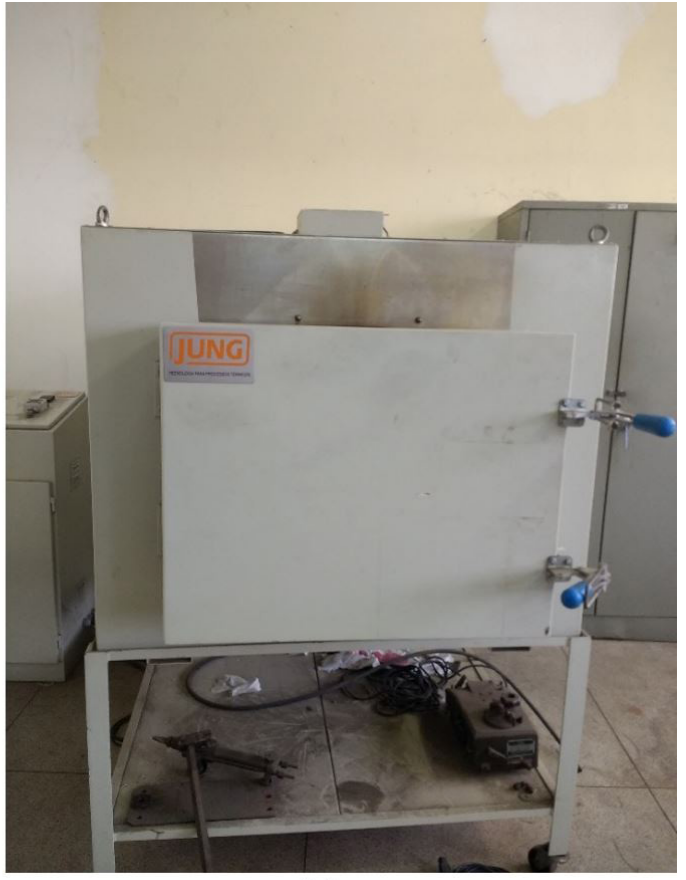

(b)

Figura 1. Equipamentos de moldagem e queima dos corpos de prova; (a) prensagem dos corpos de prova; (b) forno para queima dos corpos de prova.

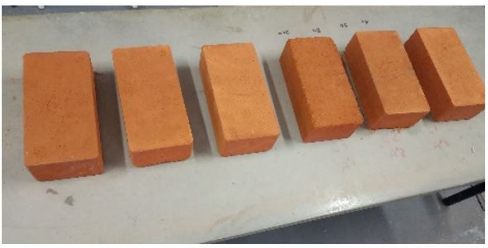

(a)

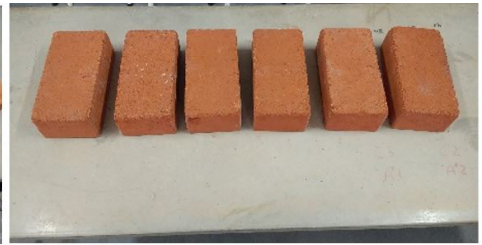

(b)

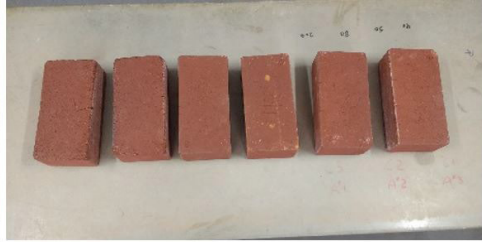

(c)

Figura 2. Pavers cerâmicos queimados nas diferentes temperaturas; (a) $950{ }^{\circ} \mathrm{C}$; (b) $1050{ }^{\circ} \mathrm{C}$; (c) $1150{ }^{\circ} \mathrm{C}$. 
Nas peças cerâmicas sinterizadas foram aferidas as características abaixo listadas;

Retração Linear de Queima;

Absorção de Água;

Massa Específica Aparente;

Resistência à Compressão;

Difração de Raios X;

Microscopia Eletrônica de Varredura.

A execução dos ensaios, nos corpos de prova queimados, seguiu as normatizações das ABNT MB-3055, NBR 12.766/92 ${ }^{6}$ e NBR 9781/137 . Na difração de raios X utilizou-se o mesmo equipamento citado acima. No ensaio de microscopia eletrônica de varredura utilizou-se o modelo SSX-550 da marca SHIMADZU. Os procedimentos normativos foram realizados no laboratório de materiais do IFPI, com exceção do ensaio de resistência à compressão que foi executado no laboratório mecânico da UNIFSA.

\section{Resultados e Discussões}

\subsection{Resultados de caracterização da matéria-prima}

Os limites de consistência de Atterberg podem ser classificados segundo Senai ${ }^{8}$, conforme consta na tabela 1 .

Para se verificar a plasticidade da amostra argilosa precisa-se obter antes os valores de limite de liquidez (LL) e limite de plasticidade (LP) para em seguida aplicar a expressão IP = LL - LP, conforme a NBR 7180/16 ${ }^{4}$.

Os resultados obtidos dos limites de consistência realizados na matéria-prima estão representados na tabela 2, onde foi classificada como excelente, conforme classificação acima.

Conforme os resultados obtidos nos ensaios de composição mineralógica (DRX), composição química (FRX) e análise racional ilustrados na Figura 3 e Tabelas 3 e 4, respectivamente, a amostra de argila analisada apresenta, predominantemente, materiais argilosos do grupo ilita $\left[\left(\mathrm{K}_{3} \mathrm{H}_{3} \mathrm{O}\right) \mathrm{Al}_{2} \mathrm{Si}_{3} \mathrm{Al}_{10}(\mathrm{OH})_{2}\right]$ que é amplamente utilizada na produção de produtos de base vermelha. A presença do quartzo na massa melhora a secagem e a liberação de gases de queima, minimizando a retração além de apresentar um importante papel na microestrutura da peça cerâmica. A dolomita encontrada contribui na melhoria da estabilidade dimensional e resistência mecânica dos corpos cerâmicos.

No ensaio termogravimétrico, figura 4 , observa-se que para a faixa de temperatura de $450{ }^{\circ} \mathrm{C}$ e $625^{\circ} \mathrm{C}$ ocorre a maior perda de massa decorrente da queima da matéria orgânica e da dissociação da água de constituição dos argilominerais. $\mathrm{Na}$ faixa de $625^{\circ} \mathrm{C}$ a $1150{ }^{\circ} \mathrm{C}$ a perda de $2,8 \%$ deve-se principalmente a decomposição da dolomita com a saída do $\mathrm{CO}_{2}$.

\subsection{Caracterização física dos corpos de prova queimados}

A Tabela 5 e a Figura 5 apresentam os resultados dos ensaios de Retração Linear de Queima (RLQ), Absorção de Água (AA), Massa Específica Aparente (MEA) e Resistência à Compressão (RC). Observa-se que as retrações de queima crescem com o aumento da temperatura de queima. Isto ocorre devido a maior densificação dos corpos cerâmicos, decorrentes da mais intensa sinterização. Vale informar que as normas para pavers cerâmicos não especificam requisitos quanto a RLQ, mas observou-se que na temperatura de $1150{ }^{\circ} \mathrm{C}$ apresentou a maior retração linear de queima, favorecendo a estabilidade dimensional do produto cerâmico.

O resultado da absorção de água indica uma redução significativa com o aumento da temperatura. Esta redução deve estar atribuída ao maior grau de sinterização adquirida com o crescimento da temperatura de queima, ratificando com o aumento da retração linear de queima. Os dados obtidos da massa específica mostram um aumento gradual com a elevação da temperatura de queima, o que se justifica pela sinterização por fluxo viscoso (vitrificação)

Tabela 1. Classificação da argila ou caulim, quanto ao índice de plasticidade.

\begin{tabular}{ccccccc}
\hline Argilas & $\begin{array}{c}\text { Excessivamente } \\
\text { plástica }\end{array}$ & Excelente & Boa & Regular & Fraca & $\begin{array}{c}\text { Material de } \\
\text { capa }\end{array}$ \\
\hline $\begin{array}{c}\text { Índice de } \\
\text { Plasticidade (\%) }\end{array}$ & 19 a 25 & 17 a 18 & 15 a 16 & 13 a 14 & 11 a 12 & 5 a 10 \\
\hline
\end{tabular}

Tabela 2. Limites de consistência de Atterberg da matéria-prima.

\begin{tabular}{ccccc}
\hline Matéria-prima & $\begin{array}{c}\text { Limite de Liquidez } \\
(\%)\end{array}$ & $\begin{array}{c}\text { Limite de } \\
\text { Plasticidade (\%) }\end{array}$ & $\begin{array}{c}\text { Índice de } \\
\text { plasticidade (\%) }\end{array}$ & Classificação \\
\hline Massa argilosa & 45 & 27 & 18 & Excelente \\
\hline
\end{tabular}

Tabela 3. Análise química por fluorescência de raios X.

\begin{tabular}{ccccccccc}
\hline \multirow{2}{*}{ Amostra } & \multicolumn{6}{c}{ Análise Química por Florescência de Raios X da Matéria-prima (\% em peso) } \\
\cline { 2 - 23 } & SiO2 & $\mathbf{A l 2 O 3}$ & Fe2O3 & K2O & CaO2 & MgO & TiO3 & Outros \\
\hline Massa Cerâmica & 55,19 & 20,65 & 12,63 & 5,43 & 1,34 & 2,41 & 1,53 & 0,82 \\
\hline
\end{tabular}


Tabela 4. Concentração das fases cristalinas da massa cerâmica.

\begin{tabular}{cccc}
\hline \multicolumn{4}{c}{ Fases identificadas (\%) } \\
\hline Matéria-prima & ilita & quartzo & dolomita \\
\hline Massa cerâmica & 60,50 & 36,00 & 3,50 \\
\hline
\end{tabular}

Tabela 5. Ensaios físicos dos corpos de prova queimados nas diferentes temperaturas.

\begin{tabular}{|c|c|c|c|c|}
\hline TEMPERATURA & RLQ (\%) & AA $(\%)$ & $\operatorname{MEA}\left(\mathrm{g} / \mathrm{cm}^{3}\right)$ & RC (MPa) \\
\hline $950^{\circ} \mathrm{C}$ & 1,39 & 23,05 & 1,59 & 7,52 \\
\hline $1050^{\circ} \mathrm{C}$ & 3,94 & 17,78 & 1,7 & 9,52 \\
\hline $1150^{\circ} \mathrm{C}$ & 7,11 & 9,83 & 1,92 & 34,38 \\
\hline
\end{tabular}

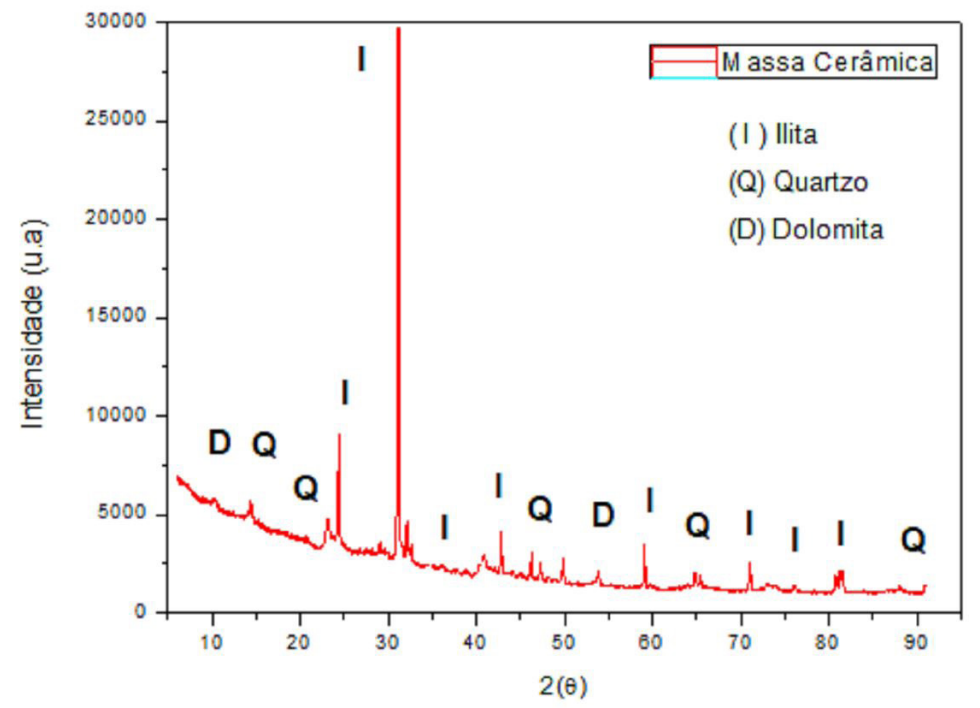

Figura 3. Difratograma de raios $X$.

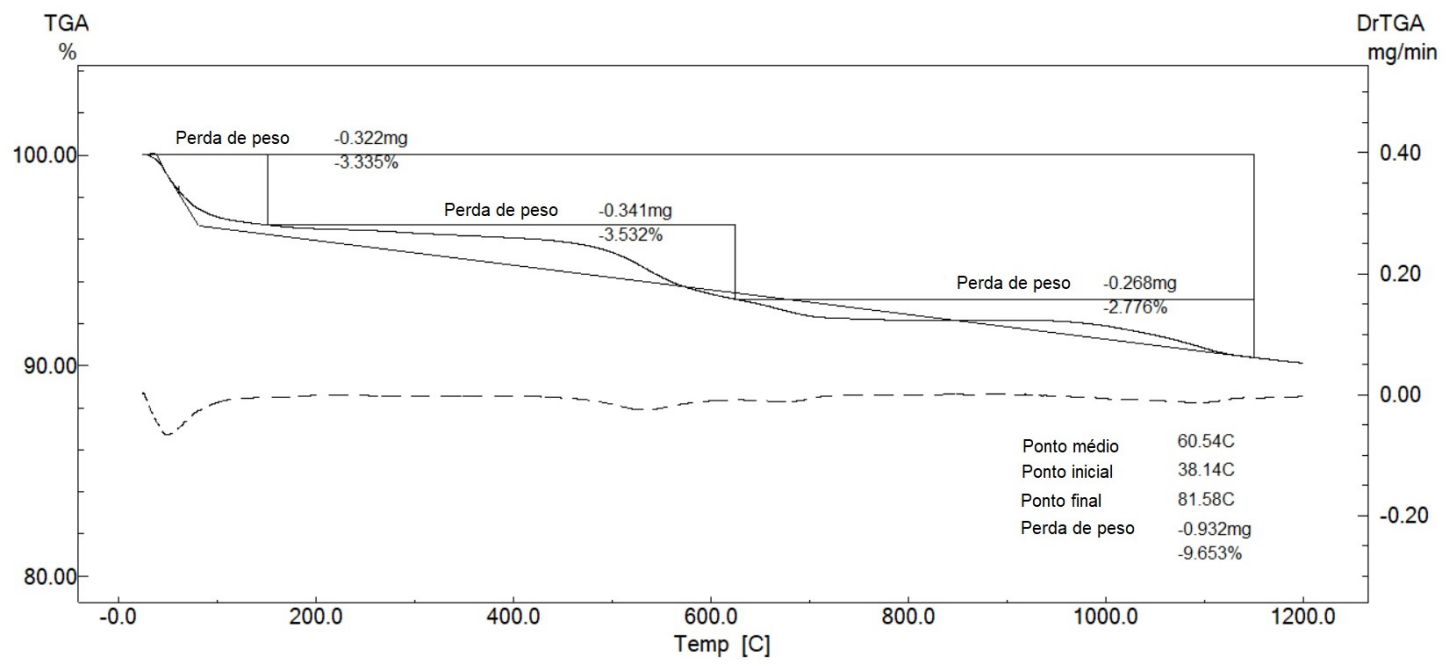

Figura 4. Curva termogravimétrica (TG) com derivada (DTG) da massa cerâmica. 
contribuindo na densificação dos corpos de prova, e estando de acordo com a RLQ e AA, pois quanto maior a densidade do corpo cerâmico menor os espaços vazios no seu interior.

No ensaio de resistência à compressão, observa-se, entre as temperaturas de $1050^{\circ} \mathrm{C}$ e $1150{ }^{\circ} \mathrm{C}$, um enorme incremento de resistência mecânica, corroborando com os ensaios de MEA e RLQ. Isto se deve provavelmente a uma maior formação de fase líquida (vitrificação) na temperatura de $1150{ }^{\circ} \mathrm{C}$.

\subsection{Caracterização microestrutural dos corpos de prova queimados}

Nos respectivos difratogramas verificam-se picos de difração das fases cristalinas referentes a quartzo $\left(\mathrm{SiO}_{2}\right)$, ortoclásio $\left(\mathrm{KAlSi}_{3} \mathrm{O}_{8}\right)$, hematita $\left(\mathrm{Fe}_{2} \mathrm{O}_{3}\right)$, espinélio $\left(\mathrm{Al}_{2} \mathrm{MgO}_{4}\right)$ e mulita $\left(\mathrm{Al}_{6} \mathrm{Si}_{2} \mathrm{O}_{13}\right)$ corroborando com o FRX que identificou os óxidos de silício, alumínio, ferro, potássio e magnésio. Observando as figuras 6-8, o quartzo e a hematita são fases presentes em todas as temperaturas estudadas e devido ao seu alto ponto de fusão o quartzo é a fase predominante. $\mathrm{O}$ ortoclásio é identificado somente na temperatura de $950{ }^{\circ} \mathrm{C}$, justificando o maior valor de AA e os menores valores de RLQ e RC. O espinélio e a mulita foram identificados somente na temperatura de $1150{ }^{\circ} \mathrm{C}$, o que justifica o aumento de aproximadamente $260 \%$ da resistência mecânica em relação aos queimados na temperatura de $1050^{\circ} \mathrm{C}$.

A figura 9 apresenta as micrografias da região fraturada dos corpos de prova nas temperaturas de $950^{\circ} \mathrm{C}$ e $1150^{\circ} \mathrm{C}$ com ampliações de 300 e 600 vezes, respectivamente, no qual observa-se que as micrografias (a) e (b) mostram uma topografia mais grosseira e rugosa, maior quantidade de poros com maior tamanho e de forma irregulares, indicando uma sinterização menos acentuada em comparação com as micrografias (c) e (d), que mostram uma topografia característica de um corpo cerâmico com bom nível de sinterização, ou seja, uma estrutura lisa e bastante vitrificada, apresentado poros isolados e de forma esférica que caracterizam a fase final de sinterização.

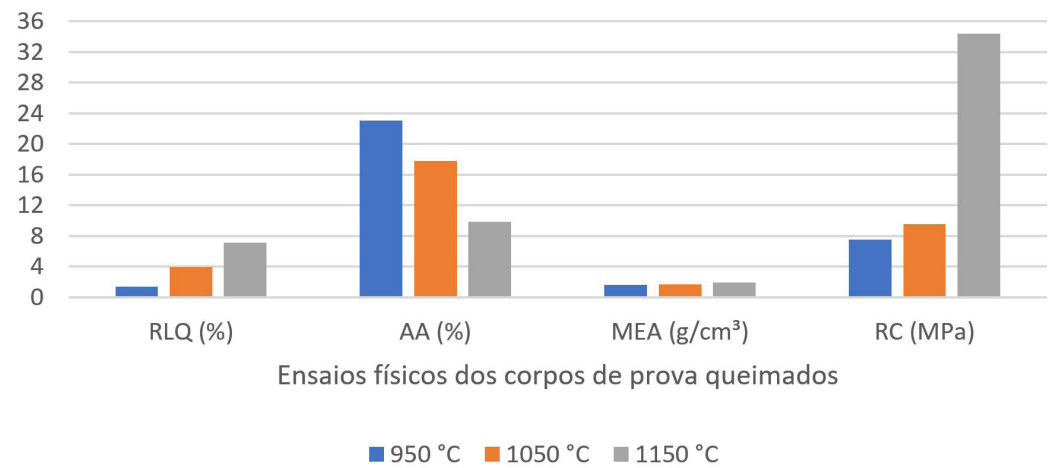

Figura 5. Gráfico dos ensaios físicos dos corpos de prova queimados nas diferentes temperaturas; RLQ - Retração Linear de Queima; AA - Absorção de Água; MEA - Massa Específica Aparente; RC - Resistência à Compressão.

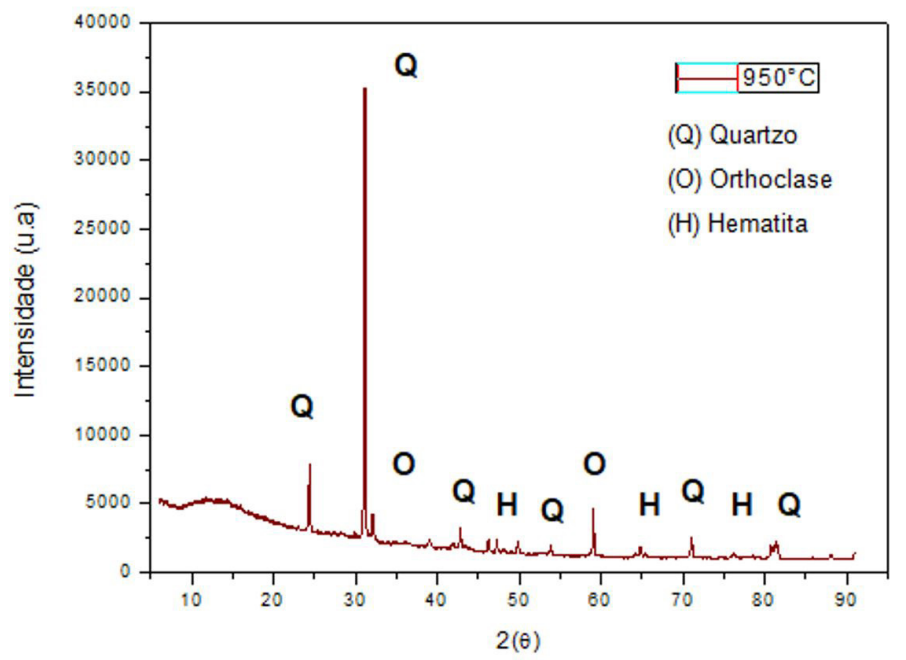

Figura 6. Difração de raios $\mathrm{X}$ do corpo de prova queimado a $950{ }^{\circ} \mathrm{C}$. 


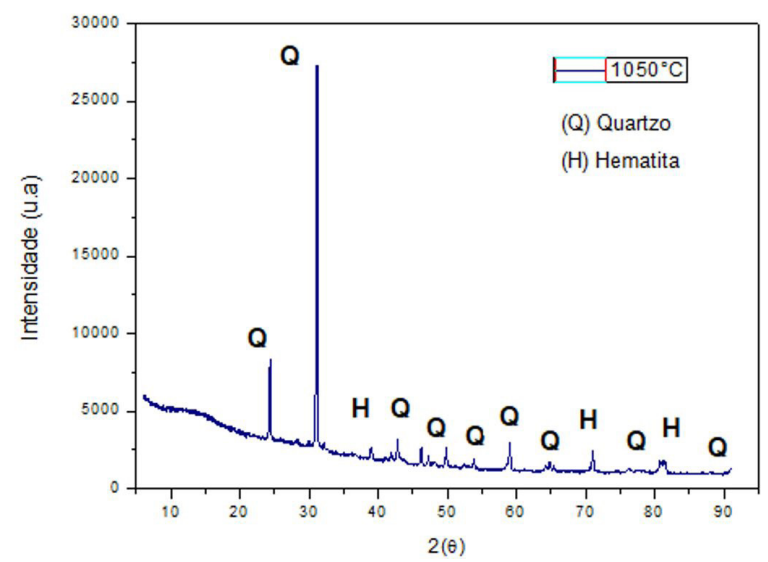

Figura 7. Difração de raios $\mathrm{X}$ do corpo de prova queimado a $1050{ }^{\circ} \mathrm{C}$.

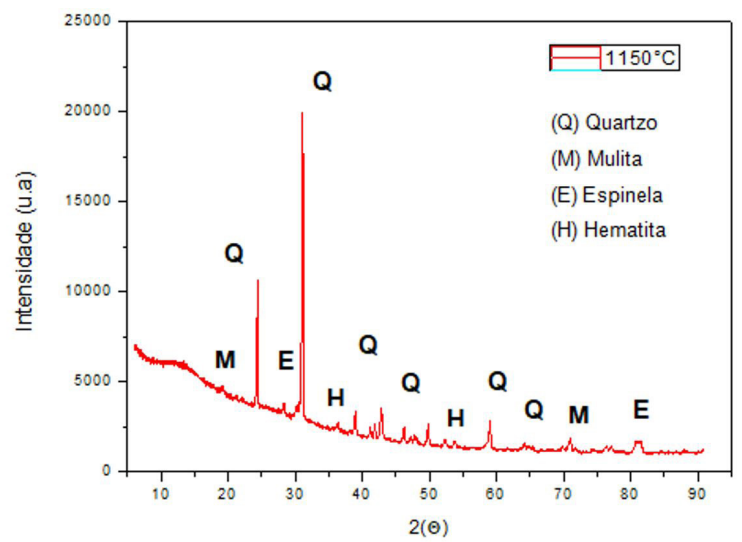

Figura 8. Difração de raios $\mathrm{X}$ do corpo de prova queimado a $1150{ }^{\circ} \mathrm{C}$.

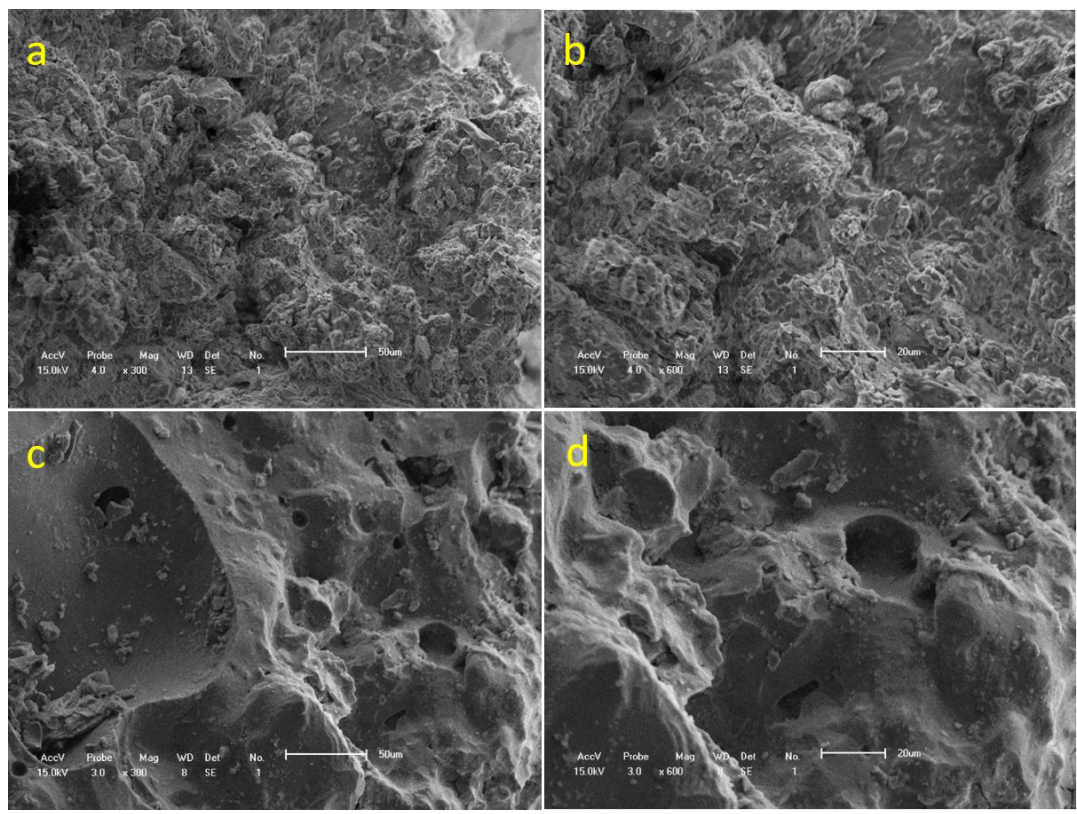

Figura 9. Fotomicrografias por MEV da superfície de fratura dos corpos de prova na temperatura de $950{ }^{\circ} \mathrm{C}$ (a) $300 \mathrm{x}$ e (b) $600 \mathrm{x}$ e na temperatura de $1150{ }^{\circ} \mathrm{C}$ (c) $300 \mathrm{x}$ e (d) $600 \mathrm{x}$. 


\section{Conclusão}

As análises química, mineralógica e térmica mostraram que a massa argilosa estudada é formada por argilas fundentes de queima vermelha com alto teor do argilomineral ilita, ou seja, são argilas típicas aplicadas na fabricação de produtos cerâmicos estruturais.

$\mathrm{O}$ aumento das temperaturas de queima dos corpos de prova influenciou positivamente as propriedades de absorção de água, massa específica aparente e resistência mecânica. O resultado de absorção de água mostrou um maior fechamento dos poros com o aumento da temperatura de queima. Este resultado é corroborado com o aumento da massa específica aparente no qual apresentou um aumento gradual com o incremento da temperatura.

$\mathrm{O}$ ensaio de resistência à compressão mostrou que o resultado na temperatura de $1150{ }^{\circ} \mathrm{C}$ obteve o maior valor entre as três temperaturas estudadas, justificado principalmente pela formação de fase liquida (vitrificação) pelas formações do espinélio e mulita corroborados pelos difratogramas de queimas e pelas fotomicrografias por MEV.

Os resultados mostraram que o uso da massa cerâmica utilizada na fabricação de telhas prensadas é uma alternativa viável para produção do pavimento cerâmico, Adoquim, tendo em vista as características adquiridas, principalmente na resistência mecânica e absorção de água.

\section{Referências}

1 ABC ASSOCIAÇÃO BRASILEIRA DE CERÂMICA. Cerâmica no Brasil- número do setor. Disponível em: $<$ http:// www.abeceram.org.br>. Acesso em: 07 de março de 2018.

2 VIVONA, D, Visão, desafios e novos rumos da cerâmica de revestimento. Cerâmica Industrial, 5, 2 (2000) 17.

3 ABNT - Associação Brasileira de Normas Técnicas. NBR6459 - Solo Determinação do limite de liquidez. Rio de Janeiro, 2016.

4 ABNT - Associação Brasileira de Normas Técnicas. NBR 7180 - Determinação do limite de plasticidade: método de ensaio. Rio de Janeiro. ABNT, 2016.

5 ABNT.MB 305: Associação Brasileira de Normas Técnicas - Argila, argamassas, concreto e cimento refratário Determinação da retração linear após secagem. Rio de Janeiro, 1987.

6 ABNT - Associação Brasileira de Normas Técnicas. NBR12766 - Rochas para revestimento - Determinação da massa específica aparente e absorção d'água aparente, Rio de Janeiro, 1992, 02p.

7 ABNT - Associação Brasileira de Normas Técnicas. NBR 9781 - Peças de concreto para pavimentação - Especificações e Métodos de Ensaio. Rio de Janeiro. ABNT, 2013.

8 SENAI. Departamento Regional do Piauí. Especial de Tecnologia em Cerâmica Vermelha. Teresina - PI, 2008. 